\title{
QUALIDADE DE MELÃo RENDILHADO (Cucumis melo L.) EM FUNÇÃo DO SISTEMA DE CULTIVO
}

\author{
Quality of net melon (Cucumis melo $\mathbf{L}$.) in function of the culture system
}

\author{
Pablo Forlan Vargas ${ }^{1}$, Renata Castoldi², Hamilton César de Oliveira Charlo², Leila Trevizan Braz ${ }^{3}$
}

\begin{abstract}
RESUMO
Objetivou-se com este trabalho avaliar a qualidade de frutos de cinco cultivares de melão rendilhado (Cucumis melo L.), cultivados em casa de vegetação, em função do sistema de produção. O experimento foi instalado em casa de vegetação na UNESPFCAV, Jaboticabal-SP, no período de novembro de 2005 à fevereiro de 2006. O experimento foi delineado em esquema fatorial 5 X 2 , em blocos casualizados com quatro repetições. Os tratamentos resultaram da combinação de cinco híbridos de melão rendilhado: Maxim, Bônus 2, Shinju 200, Fantasy e Louis e dois sistemas de cultivo: no solo e em substrato de fibra da casca de coco. As características avaliadas foram: massa fresca do fruto, espessura de mesocarpo, intensidade de rendilhamento da casca, $\mathrm{pH}$, sólidos solúveis totais, acidez titulável, índice de maturação (RATIO), e vitamina C. Não houve interação significativa entre os sistemas de cultivo e cultivares para nenhuma das características avaliadas. O cultivo de melão em substrato resultou em frutos com qualidade superior ao cultivo em solo. Os híbridos Louis e Fantasy foram os que apresentaram melhor desempenho qualitativo de frutos.
\end{abstract}

Termos para indexação: Cucumis melo, cultivares, pós-colheita.

\section{ABSTRACT}

The aim of this study was to evaluate the fruit quality of five net melon (Cucumis melo L.) cultivars, grown in a greenhouse, in function of production system. The study was carried out in a greenhouse at UNESP-FCAV, Jaboticabal-SP, Brazil, during the period of November, 2005 to February, 2006. The study was carried out using a 5 x 2 factorial scheme, in randomized complete block design with four repetitions. The treatments resulted the combination of five net melon hybrids: Maxim, Bônus 2, Shinju 200, Fantasy and Louis and two cultivations systems: in soil and in coconut fiber substrate. The characters evaluated were: fresh weight of fruit, mesocarp thickness, fruit shape index, $\mathrm{pH}$, total soluble solids, titratable acidity, maturation index (RATIO); and vitamin C. No interactions were observed between cultivated system and cultivars for characteristics examined. The melon cultivation in substrate provided in fruits with better performance when compared to cultivation in soil. The hybrids Louis and Fantasy show the best performance quality of fruits.

Index terms: Cucumis melo, cultivars, postharvest.

(Recebido em 20 de novembro de 2006 e aprovado em 10 de agosto de 2007)

\section{INTRODUÇÃO}

O melão (Cucumis melo L.) é uma hortaliça muito consumida e de grande popularidade no mundo. O Brasil produziu, em 2005, 190 mil toneladas de melão (FAO, 2006), apresentando fortes tendências de crescimento em função do consumo interno e das exportações.

$\mathrm{Na}$ literatura, encontra-se pouca informação relativa à quantidade de área plantada com melões do grupo reticulatus no Brasil, uma vez que a maior expressividade de plantio ocorre para o melão do grupo inodorus.
O consumo de melão rendilhado está relacionado ao teor de sólidos solúveis, responsável pelo sabor e o seu aspecto visual, que o diferencia dos outros tipos de melões existentes no mercado. Sua qualidade nutricional também tem contribuído favoravelmente para o seu consumo, pois é considerado pouco calórico e boa fonte de sódio, potássio, vitaminas A e C e beta-caroteno (LESTER, 1997).

A qualidade em frutos de melão envolve atributos relacionados às características da polpa (McCREIGHT et al., 1993), como sólidos solúveis, aparência interna e externa

\footnotetext{
${ }^{1}$ Engenheiro Agrônomo, Doutorando em Agronomia - Departamento de Produção Vegetal - Faculdade de Ciências Agrárias e Veterinárias/FCAV - Universidade Estadual Paulista/UNESP - Via de Acesso Professor Paulo Donato Castellane, s/n - 14884-900 Jaboticabal, SP - pfvargas@ fcav.unesp.br

${ }^{2}$ Engenheiros Agrônomos, Mestrandos em Agronomia - Departamento de Produção Vegetal - Faculdade de Veterinárias/FCAV Universidade Estadual Paulista/UNESP - Via de Acesso Professor Paulo Donato Castellane, s/n - 14884-900 - Jaboticabal, SP _ rcastoldi@gmail.com, hamiltoncharlo@gmail.com

${ }^{3}$ Engenheira Agrônoma, Doutora, Professora Adjunta - Departamento de Produção Vegetal - Faculdade de Ciências Agrárias e Veterinárias/FCAV - Universidade Estadual Paulista/UNESP - Via de Acesso Professor Paulo Donato Castellane, s/n - 14884-900 Jaboticabal, SP - leilatb@fcav.unesp.br
} 
do fruto (MENEZES et al., 2001), espessura de polpa e "flavor", indicando a aceitabilidade do consumidor.

O teor de sólidos solúveis é usado como índice de classificação de melões de acordo com seu grau de doçura, sendo menor de $9^{\circ}$ Brix, considerados não comercializáveis, de $9^{\circ}$ a $12^{\circ}$, comercializáveis e acima de $12^{\circ}$, melão extra havendo mercado para frutos de 0,8 a $2,0 \mathrm{~kg}$ fruto $^{-1}$ (GORGATTI NETO et al., 1994).

Essa qualidade está relacionada ao manejo que a cultura recebe até o momento da colheita (CHITARRA \& CHITARRA, 1990). Sales Júnior et al. (2004) afirmam que as condições de cultivo afetam diretamente as características relacionadas com a qualidade dos frutos.

Com a consolidação do cultivo de hortaliças em casa de vegetação, o cultivo do melão rendilhado recebeu maior atenção dos produtores, especialmente nos estados de São Paulo e Paraná, como opção rentável no cultivo protegido (PURQUERIO, 2002). Esse sistema se expandiu a partir de 1990, com a possibilidade de exportação e a perspectiva de novos nichos de mercado, com a expansão das grandes redes de supermercados no país. Dessa forma, o meloeiro está sofrendo uma sensível expansão de cultivo nesse sistema, com predominância dos melões do grupo reticulatus.

No cultivo em estufa, o meloeiro é geralmente tutorado, o que permite um melhor aproveitamento da área (PÁDUA, 2001). O cultivo protegido comparado às condições de campo apresenta inúmeras vantagens como a obtenção de um maior números de colheitas durante o ano, precocidade das colheitas, economia de água e fertilizantes, maiores rendimentos e melhor qualidade dos produtos (FARIAS, 1988).

Por outro lado, o uso intensivo do solo em ambiente protegido, acarreta maior acúmulo de sais minerais e de patógenos. Os fatores que mais contribuem para concentração de sais são a não ocorrência de chuvas, adubação mineral em excesso, irrigação por gotejamento e o uso contínuo do solo. Essa concentração ao atingir valores elevados tornam-se fitotóxicos para a maioria das culturas, reduzindo a produção (MÜLLER \& VIZZOTTO, 1999). O surgimento desses problemas e os desafios para solucioná-los têm favorecido o interesse pelo cultivo hidropônico, modelo que vem crescendo substancialmente no Brasil (MORAES \& FURLANI, 1999; PÁDUA, 2001).

O cultivo dessa olericola em sistema hidropônico permite o controle parcial das condições climáticas, menor aplicação de defensivos agrícolas, manejo adequado da água e nutrientes de acordo com o desenvolvimento da cultura e, a possibilidade de adensamento do cultivo, caracterizando- se como fatores relevantes, para incrementos significativos na produtividade e qualidade do produto final (CASAROLI et al., 2004).

Objetivou-se neste trabalho avaliar a qualidade de frutos de cinco cultivares de melão rendilhado, cultivados em casa de vegetação, em função do sistema de produção.

\section{MATERIAL E MÉTODOS}

O experimento foi conduzido em Casa de Vegetação, do Setor de Olericultura e Plantas Aromático-Medicinais do Departamento de Produção Vegetal, da Faculdade de Ciências Agrárias e Veterinárias-UNESP-Campus de Jaboticabal.

A casa de vegetação utilizada foi do tipo arco, com $50 \mathrm{~m}$ x $6 \mathrm{~m}$, pé direito de $3,5 \mathrm{~m}$, e tela de proteção lateral.

$\mathrm{O}$ experimento foi delineado em esquema fatorial 5 x 2, em blocos casualizados com quatro repetições. Os tratamentos resultaram da combinação de cinco híbridos de melão rendilhado (Maxim, Bônus $n^{\circ}$ 2, Shinju 200, Fantasy e Louis) e dois sistemas de cultivo (no solo e substrato de fibra da casca de coco). Cada parcela foi constituída por uma linha de $2,5 \mathrm{~m}$, com cinco plantas. $\mathrm{O}$ espaçamento adotado foi de $1,0 \times 0,5 \mathrm{~m}$.

A semeadura foi realizada em 10-11-2005, utilizando bandejas de poliestireno expandido com 128 células, preenchidas com substratos Plantmax HT®. O transplante para a casa de vegetação foi realizado aos 11 dias após semeadura, quando as mudas apresentavam a primeira folha definitiva.

O fornecimento de fertilizantes e água foi realizado conforme indicação para cada sistema de cultivo. A adubação de plantio, no sistema em solo, foi realizada de acordo com a análise de solo e constou de $30 \mathrm{~kg} \mathrm{ha}^{-1}$ de $\mathrm{N}$, $60 \mathrm{~kg} \mathrm{ha}^{-1} \mathrm{~K}_{2} \mathrm{O}$ e $180 \mathrm{~kg} \mathrm{ha}^{-1} \mathrm{P}_{2} \mathrm{O}_{5}$. Foram efetuadas quatro adubações em cobertura, sendo a primeira aos 15 dias após o transplante, e as demais em intervalos de 15 dias, totalizando $80 \mathrm{~kg} \mathrm{ha}^{-1}$ de $\mathrm{N}$ e $80 \mathrm{~kg} \mathrm{ha}^{-1} \mathrm{~K}_{2} \mathrm{O}$ (RAIJ et al., 1997). As irrigações foram feitas por gotejamento conforme a necessidade e desenvolvimentos da cultura. Para o cultivo em substrato foi utilizada irrigação por gotejamento com solução nutritiva recomendada para a cultura por Castellane \& Araújo (1994). A fertirrigação foi controlada por um temporizador, tendo início às 7 horas e término às 18 horas. Quando as plantas estavam na fase inicial foram realizadas um pulso de 5 minutos a cada hora, com o desenvolvimento da cultura o período foi aumentando, chegando ao final do ciclo com 15 minutos a cada hora. A vazão do gotejador utilizado para irrigação foi de $14 \mathrm{~mL} / \mathrm{min}$. 
O tutoramento das plantas foi feito com fitilhos plásticos presos a arames localizados rente ao solo e a $2 \mathrm{~m}$ de altura, e quando a planta atingiu dois metros de altura foi realizada a capação, sendo conduzida uma planta por vaso de $13 \mathrm{dm}^{3}$. Foram realizadas desbrotas (até o $8^{\circ}$ nó e após a fixação dos frutos) e amarrios das plantas sempre que necessário. O controle de pragas e doenças foi realizado de acordo com a necessidade da cultura.

A polinização foi realizada manualmente e após o pegamento dos frutos foram efetuados raleios sempre que necessário, para deixar dois frutos por planta.

Os frutos foram colhidos quando a região de abscisão apresentou rachadura em todo o seu perímetro, sendo realizadas cinco colheitas. As características avaliadas foram: massa fresca do fruto (MFF), realizada com auxílio de uma balança digital com variação de $\pm 5 \mathrm{~g}$, sendo os dados expressos em $\mathrm{kg}$; espessura de mesocarpo (EM), após corte transversal na região central do fruto foi aferida com paquímetro digital e valores expressos em milímetros; rendilhamento de casca (RC), adotando-se escala de notas conforme metodologia de Rizzo (2004), nota 1 para frutos com rendilhamento intenso, $2 \mathrm{com}$ rendilhamento médio e 3 com rendilhamento fraco; $\mathrm{pH}$, determinado no extrato do suco, com auxílio de um peagâmetro digital; sólidos solúveis totais (SST), obtidos através de refratômetro manual sendo os valores em \%, corrigidos à $20^{\circ} \mathrm{C}$; acidez titulável (AT), obtido através de uma alíquota de $10 \mathrm{~mL}$ de suco, ao qual foi adicionado 40 $\mathrm{mL}$ de água destilada e três gotas do indicador fenolftaleina alcoólica a $1 \%$. Em seguida se fez a titulação com solução de $\mathrm{NaOH} 0,1 \mathrm{~N}$, até o ponto de viragem. Os dados foram expressos em \% de ácido cítrico; índice de maturação (RATIO), obtido pela relação entre SST/AT; e vitamina C (Vit C), em mg de ácido ascórbico por $100 \mathrm{~mL}$ de suco, foi obtida através da titulação com 2,6 diclorofenol indofenol de sódio (2,6 DINa).

Para cada característica, quando o valor de $\mathrm{F}$ calculado foi significativo, realizaram comparações entre médias, pelo teste de Tukey, ao nível de 5\% de probabilidade.

\section{RESULTADOS E DISCUSSÃO}

Não houve interação significativa entre as cultivares de melão rendilhado e os sistemas de cultivo para nenhuma das características avaliadas.

Os sistemas de plantio afetaram de forma significativa a qualidade dos frutos de melão (Tabelas $1 \mathrm{e}$ 2). O sistema de cultivo em substrato registrou maior massa fresca de frutos (MFF), $1,25 \mathrm{~kg}$, quando comparado com o cultivo em solo (0,76 kg). Costa et al. (2003), avaliando a concentração de potássio na solução nutritiva e número de frutos por planta, em sistema de cultivo em NFT (nutrient film technique), verificou para a cultivar Bônus $\mathrm{n}^{\circ} 2$, com dois frutos por planta, massa média dos frutos de 0,66 kg. Rizzo \& Braz (2001), trabalhando com cinco cultivares de melão rendilhado (Sunrise, Aragon, Hales Best Jumbo, Nero e Bônus $n^{\circ}$ 2) cultivado em solo, sob casa de vegetação, verificaram massa de fruto variando de $0,356 \mathrm{~kg}$ (Aragon) à $0,693 \mathrm{~kg}$ (Bônus n ${ }^{2}$ ). Esses resultados estão próximos àqueles encontrados no presente trabalho, quando cultivado no solo $(0,76 \mathrm{~kg})$ e consideravelmente inferiores aos cultivados em substrato $(1,25 \mathrm{~kg})$. Existe uma tendência do mercado interno de consumir frutos com peso próximo de $1 \mathrm{~kg}$. $\mathrm{Na}$ Europa, existe essa mesma tendência, com exceção da Espanha que tem preferência por frutos maiores (ARAÚJO, 1999). Dessa forma, os frutos oriundos do cultivo em substrato seriam os preferenciais.

As cultivares Fantasy $(1,22 \mathrm{~kg})$, Maxim $(1,09) \mathrm{e}$ Louis $(0,95)$ foram as que apresentaram melhores desempenhos de MFF (Tabela 1). Essa variação na massa média de frutos entre os híbridos também foi verificada por outros autores (PÁDUA et al., 2003; PAIVA et al., 2000; RIZZO \& BRAZ, 2001). Anualmente, as empresas têm lançado grande número de novos híbridos, assim a adoção de qualquer um desses híbridos sem uma prévia avaliação pode acarretar prejuízos na produtividade e qualidade (NUNES et al., 2004).

A espessura do mesocarpo foi superior em melões cultivados em substrato $(37,80 \mathrm{~mm})$, em relação àqueles cultivados em solo (34,56 mm), não apresentando diferenças significativas entre as cultivares (Tabela 1). Nunes et al. (2004), trabalhando com as cultivares Hy Mark e Imperial cultivado no solo, verificaram uma espessura de 34,9 e 23,6 mm, respectivamente. Esse resultado está abaixo daqueles verificados no presente trabalho, quando se utilizou o cultivo em substrato e semelhante ao encontrado no cultivo no solo.

O rendilhamento da casca do fruto de melão não foi influenciado pelo fator cultivar, porém foi significativo para o fator sistemas de cultivo. Quando se cultivou o melão em substrato os frutos apresentaram rendilhamento mais intenso em relação aos cultivados no solo (Tabela 1). A aparência externa do fruto de melão é um atributo de qualidade (MENEZES et al., 2001), e comercialmente deseja-se melões com alta intensidade de rendilhamento pois este se torna atrativo ao consumidor (GORGATTI NETO et al., 1994).

Para o $\mathrm{pH}$, verificaram-se diferenças entre os fatores (Tabela 1). O cultivo em substrato proporcionou valores 
de $\mathrm{pH}$ superiores aqueles encontrados no solo. Já em relação ao fator cultivar, Bônus $n^{\circ} 2(6,17)$, Louis $(6,04)$ e Fantasy $(5,98)$ foram os que apresentaram as melhoras médias e Maxim $(5,63)$ apresentou o pior desempenho. Diferentemente do que foi verificado nesse trabalho, Rizzo \& Braz (2001), trabalhando com cinco cultivares de melão rendilhado, não encontraram diferenças para essa característica.

Analisando-se os valores de sólidos solúveis totais verificaram-se diferenças entre os fatores sistemas de cultivo e cultivares (Tabela 2). Quanto ao fator cultivar, pode-se observar que 'Bônus n 2' (11,24), foi superior à 'Shinju 200' $(9,40)$ e 'Maxim' $(9,00)$, não diferindo das cultivares Louis $(10,90)$ e Fantasy $(10,09)$. Considerando-se o valor mínimo de sólidos solúveis totais ( ${ }^{\circ}$ Brix) aceitável para exportação (ALVES et al., 2000), e com base nas observações desse trabalho, somente as cultivares Bônus $n^{\circ} 2$, Louis e Fantasy se enquadrariam como melão tipo exportação. No que se refere ao sistema de cultivo, o cultivo em substrato proporcionou aos frutos sólidos solúveis médios superiores aos do cultivo no solo (12,76 e 7,48 ${ }^{\circ}$ BRIX, respectivamente). Portanto, para as condições do presente estudo, frutos de melão provenientes do cultivo em substrato, foram classificados como extra (BRANDÃO FILHO \& VASCONCELLOS, 1998).

Para a característica acidez titulável, verificou-se efeito significativo somente para o fator cultivares (Tabela 2). A cultivar Maxim registrou o maior valor $(0,13)$, porém diferindo apenas de Bônus $\mathrm{n}^{\circ} 2(0,09)$.
O RATIO (SS/AT), foi significativo para ambos os fatores (Tabela 2). O cultivo do melão em substrato proporcionou um valor de RATIO superior ao de solo (119,07 e 75,58, respectivamente). Para o fator cultivar, 'Bônus n' 2' obteve o maior valor (126,00), sendo superior a ‘Shinju 200' (80,35) e 'Maxim' $(69,17)$, não diferindo das cultivares Fantasy e Louis.

Verifica-se, para a característica vitamina $\mathrm{C}$, em que não foram encontradas diferenças significativas para as cultivares, contudo, para os sistemas de cultivo pode-se observar que melões provenientes do cultivo em substrato proporcionou maior valor de vitamina $\mathrm{C}$ (Tabela 2 ).

\section{CONCLUSÃO}

Com base nos resultados obtidos, nas condições onde foram realizados, conclui-se que, o sistema de cultivo utilizando fibra da casca de coco como substrato e fertirrigação proporciona frutos de melhor qualidade em relação aos cultivados no solo, e que as cultivares Louis e Fantasy apresentaram melhor desempenho.

\section{REFERÊNCIAS BIBLIOGRÁFICAS}

ALVES, R. E.; PIMENTEL, C. R.; MAIA, C. E.; CASTRO, E. B. de; VIANA, F. M.; COSTA, F. V. da; ANDRADE, G. G. de; FILGUEIRAS, H. A. C.; ALMEIDA, J. H. S. de; MENEZES, J. B.; COSTA, J. G. de; PEREIRA, L. de S. E. Manual de melão para exportação. Brasília, DF: Embrapa, 2000. $51 \mathrm{p}$.

Tabela 1 - Características qualitativas de frutos de cinco cultivares de melão rendilhado, cultivadas em dois sistemas de cultivo. Jaboticabal, UNESP - FCAV, 2006.

\begin{tabular}{|c|c|c|c|c|}
\hline \multicolumn{5}{|c|}{ Características avaliadas $\bullet$} \\
\hline & MFF & EM & $\mathrm{RC}$ & $\mathrm{pH}$ \\
\hline Substrato & 1,25 a & 37,80 a & $1,12 \quad b$ & 6,36 a \\
\hline Solo & $0,76 \quad b$ & $34,56 \quad b$ & $2,05 \mathrm{a}$ & $5,49 \quad b$ \\
\hline \multicolumn{5}{|l|}{ Cultivares } \\
\hline Maxim & $1,09 \mathrm{ab}$ & 37,13 a & $1,53 \mathrm{a}$ & 5,63 \\
\hline Louis & $0,95 \mathrm{ab}$ & 36,47 a & $1,60 \mathrm{a}$ & $6,04 \mathrm{ab}$ \\
\hline Fantasy & 1,22 a & 38,61 a & $1,62 \mathrm{a}$ & $5,98 \quad a b$ \\
\hline Shinju 200 & $0,89 \quad b$ & 34,65 a & 1,55 a & 5,80 \\
\hline Bônus 2 & $0,88 \quad b$ & $34,01 \quad \mathrm{a}$ & $1,62 \mathrm{a}$ & $6,17 \quad a$ \\
\hline $\mathrm{CV}(\%)$ & 15,20 & 9,89 & 21,52 & 3,04 \\
\hline
\end{tabular}

- MFF = Massa Fresca do Fruto $(\mathrm{kg}) ; \mathrm{EM}=$ Espessura do Mesocarpo $(\mathrm{mm}) ; \mathrm{RC}=$ Rendilhamento de Casca $(1=$ intenso, $2=$ médio e 3 fraco); e $\mathrm{pH}$.

${ }^{1}$ Médias seguidas da mesma letra na coluna não diferem entre si pelo teste de Tukey, a 5\% de probabilidade. 
Tabela 2 - Características qualitativas de frutos em cinco cultivares de melão rendilhado, cultivadas em dois sistemas de cultivo. Jaboticabal, UNESP-FCAV, 2006.

\begin{tabular}{|c|c|c|c|c|}
\hline & \multicolumn{4}{|c|}{ Características avaliadas $\bullet$} \\
\hline & SST & $\mathrm{AT}$ & RATIO & Vit $\mathrm{C}$ \\
\hline \multicolumn{5}{|c|}{ Sistema de cultivo } \\
\hline Substrato & $12,76 \mathrm{a}^{1}$ & 0,11 a & 119,07 a & 22,65 a \\
\hline Solo & $7,48 \quad b$ & $0,10 \mathrm{a}$ & $75,58 \quad b$ & $15,77 \quad b$ \\
\hline \multicolumn{5}{|l|}{ Cultivares } \\
\hline Maxim & $9,00 \quad c$ & 0,13 a & 69,17 & 17,88 a \\
\hline Louis & $10,90 \mathrm{ab}$ & $0,11 \mathrm{ab}$ & $101,50 \mathrm{ab}$ & 19,94 a \\
\hline Fantasy & $10,09 \mathrm{abc}$ & $0,10 \mathrm{ab}$ & 109,60 a & 18,56 a \\
\hline Shinju 200 & 9,40 bc & $0,12 \mathrm{ab}$ & 80,35 bc & 17,33 a \\
\hline Bônus 2 & $11,24 \mathrm{a}$ & $0,09 \quad b$ & $126,00 \mathrm{a}$ & 22,33 a \\
\hline $\mathrm{CV}(\%)$ & 9,12 & 19,45 & 16,60 & 20,90 \\
\hline
\end{tabular}

- SST = Sólidos Solúveis totais ( ${ }^{\circ}$ Brix); AT = Acidez titulável, valores expressos \% de acido cítrico; Ratio = índice de maturação (SS/ AT); e Vit C = Vitamina C, valores expressos mg de ácido ascórbico em $100 \mathrm{ml}$ de solução.

${ }^{1}$ Médias seguidas da mesma letra na coluna não diferem entre si pelo teste de Tukey a 5\% de probabilidade.

ARAÚJO, J. L. P. Evaluación de la calidad comercial y posibilidades de mercado del melón brasileño comercizable en Europa. 1999. 285 f. Tese (Doutorado) - Universidade de Córdoba, Córdoba, 1999.

BRANDÃO FILHO, J. U. T.; VASCONCELLOS, M. A. S. A cultura do meloeiro. In: GOTO, R.; TIVELLI, S. W. (Orgs.). Produção de hortaliças em ambiente protegido: condições subtropicais. São Paulo: Funep, 1998. p. 161-193.

CASAROLI, D.; FAGAN, E. B.; SANTOS, O. S.; GARCIA, D. C.; SINCHAK, S.; RIFLE, C. Influencia do espaçamento e densidade de frutos por planta em meloeiro hidropônico. Horticultura Brasileira, Brasília, v. 22, n. 2, jul. 2004. Suplemento 1 .

CASTEllane, P. D.; ARAÚJO, J. A. C. Cultivo sem solo: hidroponia. Jaboticabal: Funep, 1994. 43 p.

CHITARRA, M. I. F.; CHITARRA, A. B. Pós-colheita de frutas e hortaliças: fisiologia e manuseio. Lavras: ESAL/ FAEPE, 1990. 320 p.

COSTA, C. C.; CECÍlIO FILHO, A. B.; CAVARIANNI, R. L.; BARBOSA, J. C. Produção do melão rendilhado em função da concentração de potássio na solução nutritiva e do número de frutos por planta. Horticultura Brasileira, Brasília, v. 22, n. 1, p. 23-27, jan./mar. 2003.
FARIAS, J. R. B. Comportamento da cultura do melão em estufa plástica, sob diferentes níveis de espaçamento, raleio e cobertura do solo. 1988. 80 f. Dissertação (Mestrado em Agronomia) - Universidade Federal de Pelotas, Pelotas, 1988.

FOOD AGRICULTURAL ORGANIZATION. Statistical: database. Disponível em: <http://www.apps.fao.org>. Acesso em: 3 nov. 2006.

GORGATTI NETO, A.; GAYET, J. P.; BLEINROTH, E. W.; MATALLO, M.; GARCIA, E. E. C.; GARCIA, A. E.; ARDITO, E. F. G.; BORDIN, M. R. Melão para exportação: procedimentos de colheita e de pós-colheita. Brasília, DF: Embrapa-SPI/FRUTEX, 1994. 37 p.

LESTER, G. Melon (Cucumis melo L.) fruit nutritional quality and health funcionality. HortTech, [S.1.], v. 7, n. 3, p. 222227, 1997.

McCREIGHT, J. D.; NERSON, H.; GRUMET, R. Melon. In: KALLOO, G.; BERGH, B. O. Genetic improvement of vegetable crops. [S.1.: s.n.], 1993. p. 267-294.

MENEZES, J. B.; GOMES JÚNIOR, J.; ARAÚJO NETO, S. E.; SIMÕES, A. N. Aramazenamento de dois genótipos de melão amarelo sob condições ambiente. Horticultura Brasileira, Brasília, v. 19, n. 1, p. 42-49, 2001. 
MORAES, C. A. G.; FURLANI, P. R. Cultivo de hortaliças de frutos em hidroponia em ambiente protegido. Informe Agropecuário, Belo Horizonte, v. 20, n. 200/201, p. 105$113,1999$.

MÜLLER, J. J. V.; VIZZOTTO, V. J. Manejo do solo para a produção de hortaliças em ambiente protegido. Informe Agropecuário, Belo Horizonte, v. 20, n. 200/201, p. 32-35, 1999.

NUNES, G. H. S.; SANTOS JÚNIOR, J. J. S.; ANDRADE, F. V.; BEZERRA NETO, F.; ALMEIDA, A. H. B.; MEDEIROS, D. C. Aspectos produtivos e de qualidade de híbridos de melão cultivados no agropolo Mossoró-Assu. Horticultura Brasileira, Brasília, v. 22, n. 4, p. 744-747, out./dez. 2004

PÁDUA, J. G. Cultivo protegido de melão rendilhado em duas épocas de plantio. 2001. 108 f. Tese (Doutorado em Agronomia) - Universidade Estadual Paulista, Jaboticabal, 2001.

PÁDUA, J. G.; BRAZ, L. T.; BANZATTO, D. A.; GUSMÃO, S. A. L. Net melon productivity under different cultivation systems, during Summer and winter. Acta Horticulturae Amsterdam, v. 607, p. 83-89, 2003.
PAIVA, W. O. de; HASSAN NETO, S.; LOPES, A. G. S. Avaliação de linhagens de melão. Horticultura Brasileira, Brasília, v. 18, n. 2, p. 109-113, jul. 2000.

PURQUERIO, L. F. V. Concentração de nitrogênio na solução nutritiva e número de frutos por planta sobre a produção e qualidade dos frutos do meloeiro. 2002. $43 \mathrm{f}$. Dissertação (Mestrado em Agronomia) - Universidade Estadual Paulista, Jaboticabal, 2002.

RAIJ, B. van; CANTARELLA, J. A.; QUAGGIO, R.; FURLANI, A. M. C. (Eds.). Recomendação de adubação e calagem para o Estado de São Paulo. 2. ed. Campinas: Instituto Agronômico, 1997.

RIZZO, A. A. do N. Obtenção e avaliação de genótipos de melão rendilhado em ambiente protegido. 2004. 38 f. Tese (Doutorado em Agronomia - Produção Vegetal) Universidade Estadual Paulista, Jaboticabal, 2004.

RIZZO, A. A. N.; BRAZ, L. T. Características de cultivares de melão rendilhado cultivadas em casa de vegetação. Horticultura Brasileira, Brasília, v. 19, n. 3, p. 370-373, nov. 2001.

SALES JÚNIOR, R. et al. Qualidade do melão exportado pelo porto de Natal. Horticultura Brasileira, Brasília, v. 22, n. 1, p. $98-100,2004$ 